$12-2008$

\title{
Silencing of MBD1 and MeCP2 in prostate-cancer-derived PC3 cells produces differential gene expression profiles and cellular phenotypes
}

Yaqinuddin Ahmed

Aga Khan University

Farhat Abbas

Aga Khan University, farhat.abbas@aku.edu

Syed S. Naqvi

Aga Khan University

Mohammad U. Bashir

Aga Khan University

Romena Qazi

Aga Khan University

See next page for additional authors

Follow this and additional works at: https://ecommons.aku.edu/pakistan_fhs_mc_surg_urol

Part of the Pathology Commons, Surgery Commons, and the Urology Commons

\section{Recommended Citation}

Ahmed, Y., Abbas, F., Naqvi, S. S., Bashir, M. U., Qazi, R., Qureshi, S. A. (2008). Silencing of MBD1 and MeCP2 in prostate-cancer-derived PC3 cells produces differential gene expression profiles and cellular phenotypes. Bioscience Reports, 28(6), 319-326.

Available at: https://ecommons.aku.edu/pakistan_fhs_mc_surg_urol/36 
Authors

Yaqinuddin Ahmed, Farhat Abbas, Syed S. Naqvi, Mohammad U. Bashir, Romena Qazi, and Sohail A. Qureshi 


\title{
Silencing of MBD1 and MeCP2 in prostate- cancer-derived PC3 cells produces differential gene expression profiles and cellular phenotypes
}

\author{
Ahmed YAQINUDDIN*, Farhat ABBAS ${ }^{1}$, Syed Z. NAQVIキ, Mohammad U. BASHIR $\neq$, Romena QAZI§ \\ and Sohail A. QURESHI*
}

*Department of Biological and Biomedical Sciences, The Aga Khan University, Stadium Road, Karachi 74800, Pakistan, †Department of Surgery, The Aga Khan University, Stadium Road, Karachi 74800, Pakistan, ¥Juma Research Laboratory, The Aga Khan University, Stadium Road, Karachi 74800, Pakistan, and §Department of Pathology and Microbiology, The Aga Khan University, Stadium Road, Karachi 74800 , Pakistan

\section{Synopsis}

Alterations in genomic CPG methylation patterns have been found to be associated with cell transformation and neoplasia. Although it is recognized that methylation of $\mathrm{CpG}$ residues negatively regulates gene expression, how the various MBPs (methyl-binding proteins) contribute to this process remains elusive. To determine whether the two well characterized proteins MeCP2 (methyl-CpG-binding protein 2) and MBD1 (methyl-CpG-binding domain 1) have distinct or redundant functions, we employed RNAi (RNA interference) to silence their expression in the prostate cancer-derived PC3 cell line, and subsequently compared cell growth, invasion and migration properties of these cell lines in addition to their respective mRNA-expression profiles. Cells devoid of MeCP2 proliferated more poorly compared with MBD1-deficient cells and the parental PC3 cells. Enhanced apoptosis was observed in MeCP2-deficient cells, whereas apoptosis in parental and MBD1-deficient cells appeared to be equivalent. Boyden chamber invasion and wound-healing migration assays showed that MBD1-silenced cells were both more invasive and migratory compared with MeCP2-silenced cells. Finally, gene chip microarray analyses showed striking differences in the mRNAexpression profiles obtained from MeCP2- and MBD1-depleted cells relative to each other as well as when compared with control cells. The results of the present study suggest that MeCP2 and MBD1 silencing appear to affect cellular processes independently in vivo and that discrete sets of genes involved in cellular proliferation, apoptosis, invasion and migration are targeted by each protein.

Key words: DNA methylation, gene expression, methyl-binding protein (MBP), methylated CpG (mCpG), RNA interference (RNAi)

\section{INTRODUCTION}

DNA methylation and histone modifications are two well-known epigenetic mechanisms that have an impact on gene expression [1]. Locus-specific DNA methylation, as well as demethylation, is required during normal development to ascertain that expression of selected genes is restricted to certain tissues. Once established, un-programmed changes in genomic DNA-methylation patterns have the potential to accidentally turn on or off genes involved in diverse cellular functions, including cell cycle, migration, apoptosis and invasion, leading sometimes to disease [2-5].
Malignancies are normally characterized by widespread hypomethylation of the genome and site-specific hypermethylation of tumour-suppressor genes [6].

The negative effect of DNA methylation on gene expression is mediated by the binding of MBPs (methyl-binding proteins) to mCpGs (methylated CpGs) with subsequent recruitment of repressor complexes [7]. The five main members of the MBD (methyl-CpG-binding domain) family of proteins are MBD1, MBD2, MBD3, MBD4 and MeCP2 (methyl-CpG-binding protein 2); a sixth member, Kiaso, is structurally unrelated to the other MBPs but represses transcription in a methylationdependent manner [8]. MeCP2, the first member of this

\footnotetext{
Abbreviations used: CDK, cyclin-dependent kinase; FCS, fetal calf serum; GFP, green fluorescent protein; HDAC, histone deacetylase; MBD, methyl-CpG-binding domain; MBP, methyl-binding protein; MCM, minichromosome maintenance; mCpG, methylated CpG; MeCP2, methyl-CpG-binding protein 2; MTT, 3-(4,5-dimethylthiazol-2-yl)-2,5-diphenyl$2 \mathrm{H}$-tetrazolium bromide; RAR- $\beta$, retinoic acid receptor $\beta$; RASSF1A, Ras association domain family protein 1A; RT-PCR, reverse transcription-PCR; shRNA, small-hairpin RNA; TRD, transcriptional repression domain.

${ }^{1}$ To whom correspondence should be addressed (email farhat.bbs@gmail.com).
} 
family to be identified, is encoded by a four exon gene. Detailed analyses of MeCP2 functional domains have revealed an MBD and a TRD (transcriptional repression domain) which recruits a repressor complex, including mSin3A (murine Swi-independent $3 \mathrm{~A}$ ) along with HDAC (histone deactylase) 1 and HDAC2 [9]. $\mathrm{MeCP} 2$ binds preferentially to mCpGs adjacent to A/T-rich sequences, and MBD2 also appears to have sequence specificity which allows it to target specific genes [10,11]. MBD3 is a nonDNA-binding protein, but influences gene expression by forming a heterodimer with MBD2 [12]. As a thymine DNA glycosylase, MBD4 is involved in DNA repair, but can also repress transcription [13].

MBD1 has a TRD, three centrally located cysteine-rich CXXC motifs and a highly conserved MBD domain at its N-terminus. The third CXXC motif is needed for methylation-independent DNA binding [14]. MBD1 mediates transcription repression by recruiting HDAC3 [15]. Preserving the repressive state of chromatin during chromosomal replication is also an activity of MBD1 which it performs by forming a transient S-phase complex with histone methylase SETDB1 (SET domain, bifurcated 1) and CAF1 (chromatin assembly factor 1) that uses $\mathrm{mCpG}$ during replication to modify chromatin [16].

Although MeCP2 and MBD1 bind to hypermethylated gene promoters and subsequently recruit repressor complexes to shut down gene transcription, whether their gene targets are specific or overlapping has thus far remained unclear. To address this issue, we focused our attention on MeCP2 and MBD1, and compared side-by-side cellular processes, such as proliferation, apoptosis, invasion and migration, in addition to mRNA-expression profiles of two cell lines in which the expression of MeCP2 and MBD1 had been silenced. Our results suggest that discrete sets of genes are supervised by MeCP2 and MBD1 in PC3 cells.

\section{MATERIALS AND METHODS}

\section{Cell culture}

The PC3 cell line was obtained from the A.T.C.C. and was maintained in RPMI 1640 medium at $37^{\circ} \mathrm{C}$ with $10 \%$ (v/v) FCS (fetal calf serum), $2 \mathrm{mM}$ L-glutamine, and 100 units $/ \mathrm{ml}$ penicillin and streptomycin sulfate (Invitrogen).

\section{Transfections}

psiRNA $^{\mathrm{TM}}$ plasmids are a family of expression vectors designed to generate shRNAs (small-hairpin RNAs) from an RNA III promoter (Invivogen). PC3 cells were transfected with a mock plasmid (control) and with plasmids validated previously which express shRNAs that target MBD1 and MeCP2 mRNAs, to produce psiMBD1 (MBD1 silenced) and psiMeCP2 (MeCP2 silenced) cell lines respectively. These vectors also harbour a GFP (green fluorescent protein)-zeocin fusion cassette for selection and for gauging transfection efficiency. Transfections were carried out using $3 \mu \mathrm{l}$ of FuGENE ${ }^{\mathrm{TM}} 6$ (Roche) and $1 \mu \mathrm{g}$ of plasmid DNA. After $48 \mathrm{~h}$ of transfection, cells were trypsinized, diluted 1:15 and cultured in medium containing $50 \mu \mathrm{g} / \mathrm{ml}$ zeocin (Invivogen), which was replaced with fresh medium every 3 days. After 3 weeks, resistant colonies (200-300 clones) were trypsinized, combined into pools, cultured in selection medium and expanded into cell lines.

\section{PCR}

RT-PCR (reverse transcription-PCR) was performed to confirm silencing of the target genes. Total RNA was extracted from control PC3 cells as well as from the silenced PC3 cell lines using TRIzol (Invitrogen). Reverse transcription was carried out with $1 \mu \mathrm{g}$ of total RNA using the First-Strand Reverse Transcription kit (Invitrogen) following the manufacturer's instructions. Subsequently, $2 \mu \mathrm{l}$ of this reverse transcription reaction was used for PCR. Oligonucleotide primer sets corresponding to MBD1 and MeCP2 were purchased from Santa Cruz Biotechnology. Semiquantitative RT-PCR for MBD1 was carried out as follows: 1 cycle of $94^{\circ} \mathrm{C}$ for $2 \mathrm{~min}$, and 35 cycles of $94^{\circ} \mathrm{C}$ for $30 \mathrm{~s}, 54^{\circ} \mathrm{C}$ for $1 \mathrm{~min}$ and $72^{\circ} \mathrm{C}$ for $1 \mathrm{~min}$, followed by $72^{\circ} \mathrm{C}$ for $7 \mathrm{~min}$. Thermocycling conditions for $\mathrm{MeCP} 2$ were identical to the conditions for MBD1, except that the annealing temperature used was $52^{\circ} \mathrm{C}$. Nested PCR conditions for MBD1 and MeCP2 were: 1 cycle of $94^{\circ} \mathrm{C}$ for $2 \mathrm{~min}$, and 20 cycles of $94^{\circ} \mathrm{C}$ for $30 \mathrm{~s}, 56^{\circ} \mathrm{C}$ for $1 \mathrm{~min}$ and $72^{\circ} \mathrm{C}$ for $1 \mathrm{~min}$, followed by $72^{\circ} \mathrm{C}$ for $7 \mathrm{~min}$. Real-time PCR was carried out on a Chrome 4 real-time cycler (Bio-Rad) for detecting and quantifying the expression of MBD1 and MeCP2 mRNAs in stably transfected cells using SYBR Green master mix and optimized primers (Superarray Biotechnology) following the manufacturer's instructions.

\section{Western Blotting}

Extracts from control, MeCP2- and MBD1-silenced cell lines were prepared by resuspending cell pellets (approx. $2 \times 10^{5}$ cells) directly in sample loading buffer $[0.125 \mathrm{M}$ Tris $/ \mathrm{HCl}$ (pH 6.8), 4\% (w/v) SDS, $20 \%$ (v/v) glycerol and 10\% (v/v) 2mercaptoethanol]. Approx. $50 \mu \mathrm{g}$ of the protein was resolved by SDS/PAGE (10\% gels) and proteins were transferred on to nitrocellulose membranes (Amersham Biosciences). After blocking overnight at $4{ }^{\circ} \mathrm{C}$ in $5 \%(\mathrm{w} / \mathrm{v})$ non-fat dried skimmed milk powder prepared in TBST (Tris-buffered saline with $0.1 \%$ Tween 20), membranes were probed with antibodies against MeCP2, MBD1 and MCM2 (minichromosome maintenance 2) (all used at 1:1000 dilution; Santa Cruz Biotechnology) for 1$2 \mathrm{~h}$ at room temperature $\left(25^{\circ} \mathrm{C}\right)$. After washing, membranes were incubated for $30 \mathrm{~min}$ at room temperature with the appropriate HRP (horseradish peroxidase)-conjugated secondary antibodies and subsequently developed with the $\mathrm{ECL}^{\circledR}$ (enhanced chemiluminescence) Western blotting system (Amersham). Actin was included as the internal loading control and detected using a specific anti- $\beta$-actin antibody (1:1000 dilution; Santa Cruz Biotechnology).

\section{MTT [3-(4,5-dimethylthiazol-2-yl)-2,5-diphenyl-2H- tetrazolium bromide] assay}

Cellular proliferation was measured using the MTT proliferation assay kit (A.T.C.C.) according to the manufacturer's instructions. 
Briefly, $10^{4}$ cells were seeded in 96-well plates and cultured in $5 \%$ (v/v) FCS for $24 \mathrm{~h}$. Before testing, $10 \mu \mathrm{l}$ of the MTT labelling reagent $(5 \mathrm{mg} / \mathrm{ml} \mathrm{MTT})$ was added to cells and the mixture was incubated for a further $4 \mathrm{~h}$ at $37^{\circ} \mathrm{C}$. Solubilizing reagent $(100 \mu \mathrm{l})$ was added and the plate was incubated overnight at $37^{\circ} \mathrm{C}$ to dissolve the formazan crystals. Absorbance was measured at an absorbance $(A)$ of $595 \mathrm{~nm}$ on a Chameleon multilabel detection platform (Hidex). Each assay was carried out in triplicate and each experiment was repeated at least twice.

\section{Apotosis assays}

Apoptosis was measured by Acridine Orange and ethidium bromide staining as described previously [17] with some modifications. Briefly, $25 \mu \mathrm{l}$ of a cell suspension $\left(1 \times 10^{5}-2 \times 10^{5}\right.$ cells $)$ was added to $25 \mu \mathrm{l}$ of Acridine Orange/ethidium bromide solution $[1: 1(\mathrm{v} / \mathrm{v})]$ (both Acridine Orange and ethidium bromide were prepared at $100 \mu \mathrm{g} / \mathrm{ml}$ in PBS) and loaded on a haemocytometer under a coverslip. Cells were counted on a grid under visible light and then dead cells (stained orange with ethidium bromide) were counted under fluorescent light. A Student's $t$ test was performed to assess the statistical significance of the results obtained. Transfected cells ( $10^{5}$ cells) were also grown on to coverslips and stained with Acridine Orange and ethidium bromide after fixation with $100 \%$ methanol. These cells were visualized using an epifluorescence microscope and photographed at $\times 100$ magnification.

\section{Boyden chamber invasion assay}

The Boyden chamber invasion assay was performed as described previously [18] with some modifications. A fixed number of cells $\left(5 \times 10^{4}\right.$ cells $\left./ \mathrm{ml}\right)$ in serum-free medium were placed into the upper chamber of the Boyden chamber, which had been pre-coated with Matrigel (polyvinyl pyrrolidone-free polycarbonate filter with 8 - $\mu \mathrm{m}$-pore-size) inserts (BD Pharmingen). The lower chamber contained serum-free medium supplemented with epidermal growth factor $(50 \mathrm{ng} / \mathrm{ml}$; Invitrogen). Cells were incubated for $24 \mathrm{~h}$, after which time the medium was removed and the upper surface of the invasion chamber insert was scrubbed with a cotton swab three times in each direction. The membrane was removed from the invasion chamber insert with a scalpel, fixed with $100 \%$ methanol and stained with Giemsa Wright stain. Cells were counted at $\times 400$ magnification in five different random fields by two independent observers. A Student's $t$ test was performed to assess the statistical significance of the invasion results obtained.

\section{Gelatin zymography}

Gelatin zymography was carried out using conditioned medium in which cells had been cultured for $24 \mathrm{~h}$. Total protein in the medium was dialysed and the concentration of protein estimated, and $20 \mu \mathrm{g}$ of protein was subjected to SDS/PAGE ( $8 \%$ gels) co-polymerized with gelatin $(2 \mathrm{mg} / \mathrm{ml})$ under non-reducing conditions. Gels were washed three times with $2.5 \%$ (v/v) Triton $\mathrm{X}-100$ for $20 \mathrm{~min}$ each and incubated for $18 \mathrm{~h}$ at $37^{\circ} \mathrm{C}$ in enzyme assay buffer [50 $\mathrm{mM}$ Tris/ $\mathrm{HCl}(\mathrm{pH} 7.5)$ and $\left.5 \mathrm{mM} \mathrm{CaCl}_{2}\right]$ to develop enzyme activity bands. After incubation, the gels were stained with $0.05 \%$ Coomassie Brilliant Blue G-250 in a mixture of methanol/acetic acid/water [2.5:1:6.5 (by vol.)] and de-stained in $4 \%(\mathrm{v} / \mathrm{v})$ methanol with $8 \%(\mathrm{v} / \mathrm{v})$ acetic acid. Gelatinolytic activities were detected as transparent bands against the background of Coomassie Brilliant Blue-stained gelatin.

\section{Cell migration assay}

Stably transfected cells were sub-cultured in 6-well plates and incubated in RPMI 1640 medium with 10\% (v/v) FCS. Confluent monolayer cells were serum-starved and incubated in the absence of growth factors in RPMI 1640 medium for $24 \mathrm{~h}$, and a wound ( $1 \mathrm{~mm}$ thick) was created using a $10 \mu \mathrm{l}$ micropipette tip. Cells were washed and incubated in serum-free medium. Cell migration was monitored at $12 \mathrm{~h}$ intervals and photographed.

\section{Gene chip expression arrays}

Total RNA was extracted from psiMBD1, psiMeCP2 and control cells by Arraygrade ${ }^{\mathrm{TM}}$ Total RNA isolation kit (SuperArray Biosciences), following the manufacturer's instructions. The integrity of the RNA was assessed by resolving $1 \mu \mathrm{g}$ of RNA on a denaturating agarose gel. The Truelabelling-AMP-2.0 kit (Superarray Biosciences) was used to convert total RNA into biotinylated cRNA. The biotinylated probe was then hybridized to a prostate-cancer-specific oligoGEarray (Superarray Biosciences) and, after washing, was developed using a Chemiluminescence detection kit (Amersham Biosciences) and the image was captured on an X-ray film. The X-ray film pattern was scanned and loaded on the GEarray Expression Analysis Suite web-based software (Superarray Biosciences) for analysis. The relative expression of 288 genes was assessed using this software and normalized against the spot intensities of house-keeping genes [e.g. actin, GAPDH (glyceraldehyde-3-phosphate dehydrogenase) and ribosomal proteins] detected on the membrane.

\section{RESULTS}

\section{Validation of MBD1-silenced as well as MeCP2-silenced prostate-derived PC3 cell lines}

To address whether the genes targeted by MBD1 and MeCP2 are distinct or overlapping, we engineered two cell lines in which their respective expression was silenced by RNAi (RNA interference). For this, prostate cancer-derived PC3 cells were stably transfected with the plasmid vectors psiRNA-MeCP2 and psiRNA-MBD1, each expressing shRNAs designed to specifically abrogate the expression of their target genes. Both plasmids expressed GFP, which allowed for easy monitoring of their cellular expression by epifluorescence microscopy. After maintaining the transfected cell lines by treatment with zeocin-containing medium for 2 weeks, mRNA levels from psiMeCP2 and psiMBD1 cells were determined by semi-quantitative RT-PCR as well as real-time PCR. Semi-quantitative RT-PCR analysis was carried out using a thermocycling program of 55 cycles, with the first 


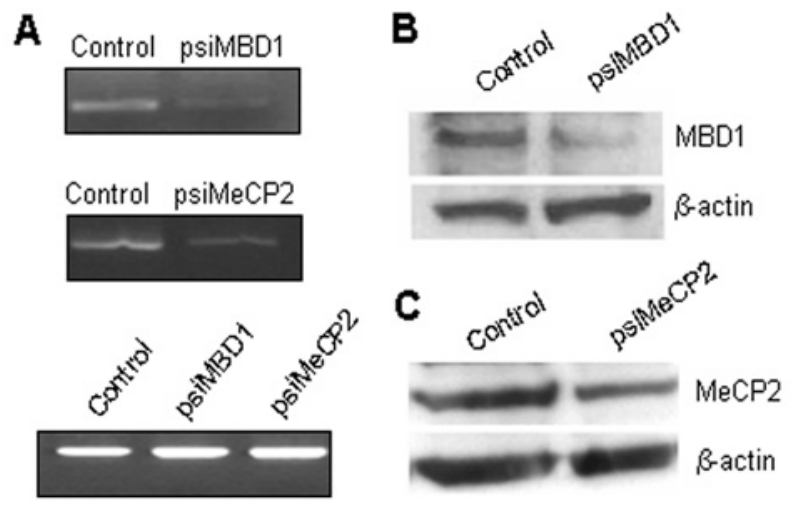

Figure 1 Silencing of MBD1 and MeCP2 expression in PC3 cells and validation of cell lines

Total RNA and protein was extracted from mock transfected (Control), psiMBD1 and psiMeCP2 PC3 cells. (A) RNA was subjected to semi-quantitative RT-PCR analysis. (B and C) Proteins were Western blotted with MBD1- and MeCP2-specific antibodies. $\beta$-Actin was used as a loading control.

35 cycles of PCR carried out using the outer primers, followed by 20 cycles of PCR with the nested primers. Agarose-gel electrophoresis analysis of the nested PCR products revealed that although the mRNAs for both MBD1 and MeCP2 were present in the psiMBD1 and psiMeCP2 cell lines respectively, their levels were significantly lower when compared with the mocktransfected PC3 cells (Figure 1A). Real-time PCR analysis also showed that after 40 cycles, MBD1 mRNA could not be detected in significant amounts in the psiMBD1 cells and that MeCP2 mRNA levels were reduced by $50 \%$ in psiMeCP2 cells (results not shown). Western blotting was also employed to determine the amounts of remaining MBD1 and MeCP2 in the silenced cell lines as well as in control cell lines. This revealed that trace amounts of MBD1 were still present in the psiMBD1 cells (Figure 1B), and the amount of $\mathrm{MeCP} 2$ protein was reduced by approx. $50 \%$ in psiMeCP2 cells relative to the control cells (Figure 1C). Overall, validation of both cell lines showed that MBD1-specific siRNA reduced expression of its target by greater than $80 \%$, whereas the attempted silencing of MeCP2 in PC3 cells resulted in only 50\% reduction in its expression levels, despite the fact that $100 \%$ of the cells were GFP positive. Additional attempts at further reducing the expression of MeCP2 in the PC3 cell line were unsuccessful.

\section{MBD1 and MeCP2 silencing produces different phenotypes in PC3 cells}

The effect of selectively silencing the expression of $\mathrm{MeCP} 2$ and MBD1 in PC3 cells on their growth and survival was studied by employing the MTT assay. It revealed a dramatic retardation of growth in both of the silenced cell lines when compared with control cells at 24 and $48 \mathrm{~h}(P<0.0001$ and $P<0.0001$ respectively) (Figure 2A). Cells devoid of $\mathrm{MeCP} 2$ grew more poorly than those in which MBD1 expression had been silenced. The observed growth defect was found to be a consequence of an enhanced rate of apoptosis, which in the psiMeCP2 cell line was approx. 2.5-fold greater than both control and psiMBD1 cell lines $(P<0.0164)$ (Figures $2 \mathrm{~B}$ and $2 \mathrm{D})$. The amount of the well known proliferation marker MCM2 in the three cell lines was quantified with Western blotting. This experiment showed that gradually lower amounts of MCM2 were found in the psiMBD1 and psiMeCP2 cells compared with control cells (Figure 2C), indicating a robust correlation between MCM2 levels and the proliferation rate of the respective cell lines.

The psiMBD1 cells were significantly more invasive than their psiMeCP2 counterparts, as demonstrated by the Boyden chamber invasion assay $(P<0.0008)$ (Figure 3A). Since invasive cells are known to secrete different matrix metalloproteinases that degrade the basement membrane, allowing cells to escape, gelatin zymography was performed on conditioned medium obtained from the control and silenced cells. This experiment showed that psiMBD1cells produced higher amounts of the $72 \mathrm{kDa}$ protein MMP2 (matrix metalloproteinase 2) compared with both the less invasive psiMeCP2 and control cells (Figure 3B).

The migratory potential of the psiMeCP2 and psiMBD1 cells was also evaluated by using the wound-healing assay. Here, control cells were able to cross the trough after $48 \mathrm{~h}$. In comparison, psiMBD1 cells migrated slower than the control cells, but significantly faster than psiMeCP2 cells (Figure 4).

\section{Expression of discrete sets of genes is influenced by MBD1 and MeCP2 silencing}

Finally, mRNA expression profiles were obtained from MBD1depleted cells, MeCP2-depleted cells and control cells by using a gene chip microarray spotted with a total of 288 oligonucleotides (including 25 control oligonucleotides) representing different genes implicated in prostate cancer. For this, total RNA was isolated from the three cell lines, labelled and hybridized to the arrays. The mRNA profiles obtained from all three cell lines are shown in Table 1. Quantitative analysis and normalization of the developed spots against housekeeping genes using the GEarray Expression Analysis Suite software showed that although the expression of a vast majority of genes in both control and psiMBD1 cells remained unchanged, expression of nine (out of 263) genes was found to be increased by at least 2-fold when MBD1 levels were reduced. Similarly, although levels of most of the expressed genes in both control and MeCP2-deficient cells also remained constant, nine completely different sets of genes were found to be up-regulated in the absence of MeCP2.

\section{DISCUSSION}

In the present study, we demonstrate that silencing of the two methyl-CpG DNA-binding proteins MBD1 and MeCP2 produces cellular phenotypes that are markedly different from each other in terms of their ability to proliferate, invade and migrate. By employing the prostate-cancer-derived PC3 cell line, and reducing markedly the expression of MBD1 or MeCP2 by RNAi, we found significant phenotypic differences between the psiMBD1 


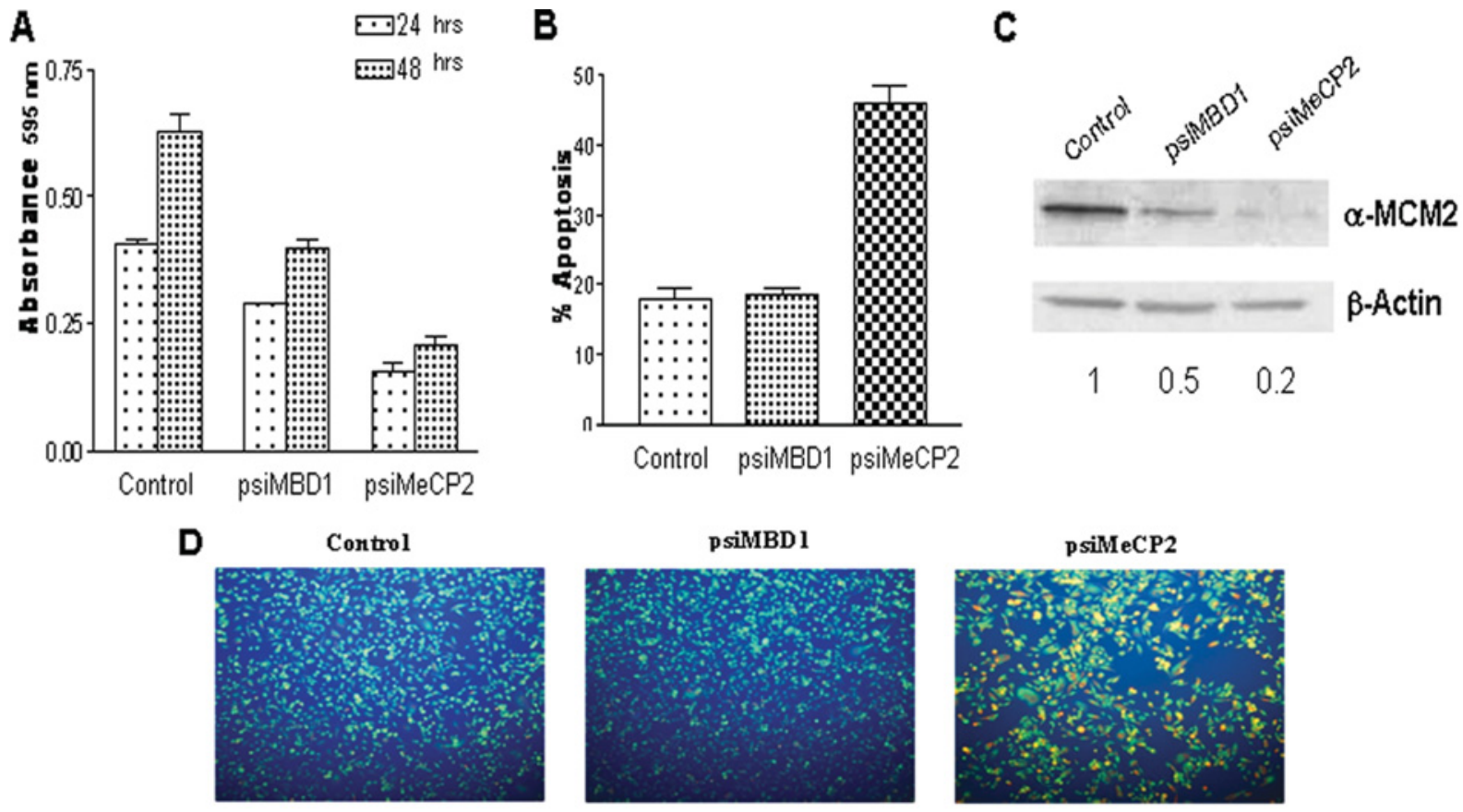

Figure 2 Effect of MBD1 and MeCP2 silencing on cell proliferation

(A) Cells [control, MBD1-depleted (psiMBD1) and MeCP2-depleted (psiMeCP2) cell lines] were grown and their respective rate of proliferation was measured using the MTT assay after culture for 24 and 48 h. Results are means \pm S.E.M. $(n=2)$ with each experiment performed in triplicate. (B) Apoptosis was measured by ethidium bromide and Acridine Orange staining of control, MBD1-depleted and MeCP2-depleted cells. Results are means \pm S.E.M. $(n=3)$. (C) Western blotting of MCM2 expression in the silenced (psiMBD1 and psiMeCP2) and control cell lines. Band intensities of MCM2 ( $\alpha$-MCM2) and $\beta$-actin were used to normalize MCM2 expression in the three cell lines (shown below the blot). (D) Acridine Orange and ethidium bromide staining of control, psiMBD1 and psiMeCP2 cells grown on coverslips and fixed with 100\% methanol, with the epifluorescene images captured at $\times 100$ magnification.

and psiMeCP2 cells. For example, proliferation of both cell lines decreased sharply, but was much more dramatic for psiMeCP2 cells. Additionally, both wound-healing and Boyden chamber assays revealed that psiMBD1cells had a greater invasion and migratory potential compared with their psiMeCP2 counterparts.

Even a 50\% reduction in MeCP2 expression levels reduced cell growth markedly. This finding is consistent with the observation that $\mathrm{MeCP} 2$ expression is required for growth of prostate cancer cells [19]. Poor growth of PC3 cells was found to be the result of enhanced apoptosis, but could also be attributed to cell-cycle arrest. Given that $\mathrm{MeCP} 2$ has been found to positively influence $c-m y c$ expression [19], it is plausible that depletion of MeCP2 in PC3 cells not only reduced expression of genes such as Cull, CDK4 (where CDK is cyclin-dependent kinase) and ornithine decarboxylase, but also the kinase activity of the CDK2/cyclin E complex that is required for cell-cycle progression [20-23]. Overall, greater than $80 \%$ reduction in MBD1 expression did not appear to have as significant an effect on the growth of $\mathrm{PC} 3$ cells compared with reducing the expression of $\mathrm{MeCP} 2$ by one-half.

On the basis of the behaviour of the engineered cell lines in our assays alone, it is tempting to speculate that processes, such as invasion and migration, are influenced more by MBD1 than MeCP2, which affects cellular growth and apoptosis, suggesting that both factors affect expression of different sets of genes. Support for this conclusion stems from the gene chip microarray results presented, which, although limited, demonstrate that MBD1 and MeCP2 appear to have distinct functions in terms of the genes that are targeted by them. Gene chip experiments showed clearly that although expression of most genes in the control and silenced cell lines remained unaltered, expression of two distinct sets of genes was affected dramatically in the absence of either factor. Among the affected genes, RASSF1A (Ras association domain family protein 1A) and $R A R-\beta$ (retinoic acid receptor $\beta$ ) were most notable, as both were significantly up-regulated in psiMeCP2 and psiMBD1 cell lines respectively. RASSF1A is a known tumour-suppressor gene which is heavily methylated in prostate cancers and is also methylated in PC3 cells [24]. Since RASSF1A is known to destabilize c-Myc via Ras inactivation [25,26], expression of RASSF1A is likely to be one reason why MeCP2-deficient cells grew so poorly. RAR- $\beta$ is a nuclear-hormone receptor whose activation by retinoic acid promotes growth arrest and apoptosis in cancer cells [27], and, given its role, it is plausible that the retarded growth and enhanced apoptosis observed in MBD1-silenced cells is a consequence of $R A R-\beta$ expression. 
Table 1 The impact of MBD1 and MeCP2 silencing on gene expression

List of genes whose expression increased in MBD1-silenced (psiMBD1) and MeCP2-silenced (psiMeCP2) cells by at least 2 -fold relative to the control PC3 cells. The expression profile of each cell line was normalized against housekeeping genes, including actin, GAPDH (glyceraldehyde-3-phosphate dehydrogenase), ribosomal proteins and blank spots on oligonucleotide arrays. AKAP1, A-kinase-anchoring protein 1; AKT, protein kinase B; BAK1, Bcl2-antagonist/killer 1; BMP6, bone morphogenetic protein 6; Cant1, calcium-activated nucleotidase 1; Cav1, caveolin 1; CCND1, cell cycle regulatory protein cyclin D1; MAPK10, mitogen-activated protein kinase 10; NTN4, netrin 4.

\begin{tabular}{llc}
\hline Gene & Function & Fold change \\
\hline Control cells compared with psiMBD1 cells & & \\
AKAP1 & Prostate cancer marker & 2.9 \\
$A K T$ & Anti-apoptotis & 2.3 \\
BAX & Apoptosis & 3.0 \\
BMP6 & Growth factor & 2.0 \\
CDK6 & Cell-cycle regulator & 2.6 \\
CDK9 & Cell-cycle regulator & 2.5 \\
MAPK10 & Jun kinase & 29.7 \\
Jun & Transcription factor & 11.7 \\
RAR- 3 & Transcription factor & 6.8 \\
Control cells compared with psiMeCP2 cells & & \\
BAK1 & Apoptosis & 3.9 \\
Cant1 & Prostate cancer marker & 4.0 \\
Cav1 & Prostate cancer marker & 8.5 \\
CCND1 & Cell-cycle regulator & 4.1 \\
CD164 & Negative regulator of cell proliferation & 2.5 \\
Enolase 2 & Prostate cancer marker & 2.5 \\
RASSF1A & Cell-cycle arrest & 2.6 \\
NTN4 & Extracellular matrix protein & 9.7 \\
\hline
\end{tabular}
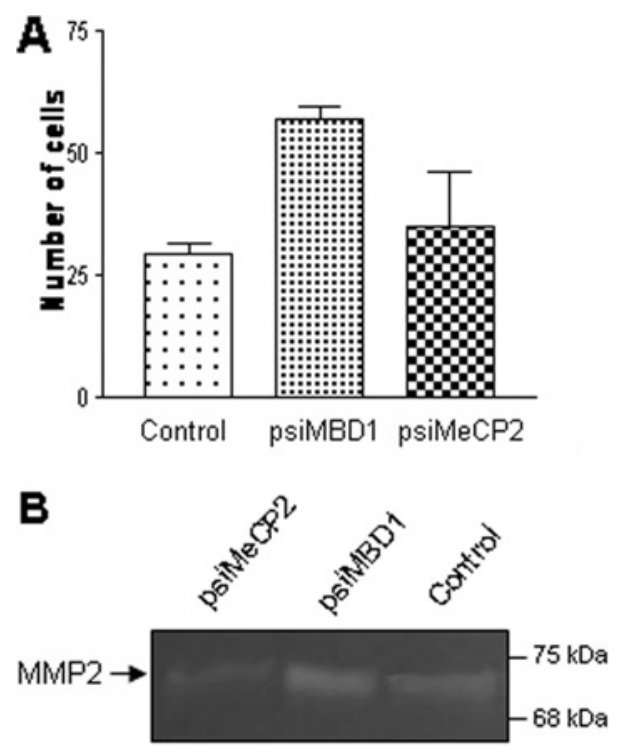

Figure 3 Cellular invasion assays and zymography analysis

(A) Boyden chamber invasion assays were carried out on control, MBD1-silenced (psiMBD1) and MeCP2-silenced (psiMeCP2) cell lines and the number of cells invading the Matrigel was determined. Results are means \pm S.E.M. $(n=2)$ with each experiment performed in triplicate. (B) Gelatin zymography was carried out with equivalent amounts of conditioned medium obtained from control and silenced (psiMeCP2 and psiMBD1) cell lines. MMP2 (matrix metalloproteinase 2) was identified as a $72 \mathrm{kDa}$ protein.
0 hrs
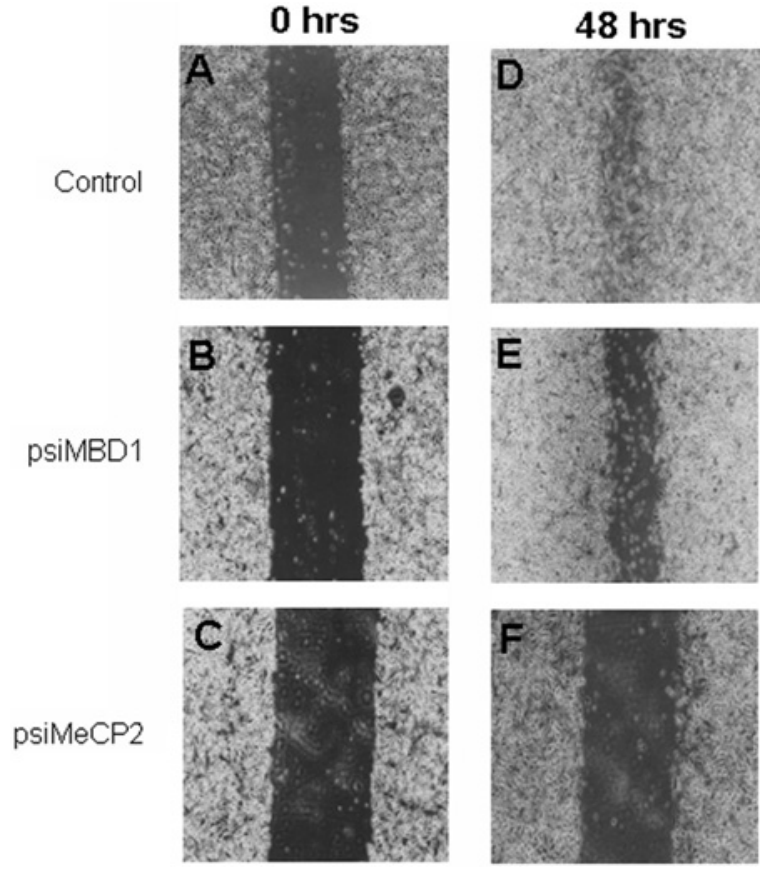

Figure 4 Cellular migration assays

Wound-healing migration assays were carried out as described in the Materials and methods section. Images show wounds in control, and MBD1-silenced (psiMBD1) and MeCP2-silenced (psiMeCP2) cells at $\mathrm{O}$ (A-C) and after $48 \mathrm{~h}(\mathrm{D}-\mathrm{F})$. 
The notion that MeCP2 is a global regulator of methylationdependent gene expression was initially based on the observation that it requires only a single $\mathrm{mCpG}$ for binding, but two key discoveries were instrumental in disputing this claim. First, a microarray-based study demonstrated MeCP2 targets only a small set of genes and affects their expression subtly [28]. Secondly, MeCP2 selectively binds to those mCpGs that are flanked by A/T residues [10,11]. Unlike MeCP2, MBD1 can bind to $\mathrm{mCpG}$ dinucleotides on double-stranded DNA regardless of its nearest neighbours and seems to be the only MBP without any sequence preference [29]. Given the $\mathrm{mCpG}$-binding properties of MBD1 and MeCP2, it is likely that genes targeted by MeCP2 necessarily serve as platforms for MBD1 binding, but not vice versa. Thus in situations where expression of $\mathrm{MeCP} 2$ is limiting, MBD1 could potentially compensate for its deficiency. In the present study, however, we found that MBD1 was unable to compensate for $\mathrm{MeCP} 2$, suggesting that $\mathrm{MeCP} 2$ regulates a set of pro-apoptotic genes either directly or indirectly which are not targets of MBD1. Interestingly, in addition to mediating its effect via $\mathrm{mCpG}$ residues, $\mathrm{MeCP} 2$ has also been shown to repress its target gene expression in a methyl-CpG independent manner $[19,30]$.

Taken together, the present study demonstrates that discrete sets of genes involved in cell proliferation, invasion and migration are selectively influenced by MBD1 and MeCP2. A detailed microarray-based transcriptome analysis of MBD1- and MeCP2-silenced cells should be useful for identifying complete sets of genes that are exclusively or commonly targeted by these proteins.

\section{ACKNOWLEDGEMENTS}

We thank Dr Anwar A. Siddiqui for encouragement and support provided to us, and Dr John D. Connor for proofreading the manuscript prior to acceptance.

\section{FUNDING}

This work was supported by The Aga University Research Council [grant number 042030PHD] awarded to A.Y. A.Y. was supported by a pre-doctoral Fellowship from the The Aga Khan University.

\section{REFERENCES}

1 Esteller, M. (2007) Cancer epigenomics: DNA methylomes and histone-modification maps. Nat. Rev. Genet. 8, 286-298

2 Zhang, Z., Sun, D., Van do, N., Tang, A., Hu, L. and Huang, G. (2007) Inactivation of RASSF2A by promoter methylation correlates with lymph node metastasis in nasopharyngeal carcinoma. Int. J. Cancer 120, 32-38

3 Sakuma, M., Akahira, J., Ito, K., Niikura, H., Moriya, T., Okamura, K., Sasano, H. and Yaegashi, N. (2007) Promoter methylation status of the cyclin D2 gene is associated with poor prognosis in human epithelial ovarian cancer. Cancer Sci. 98, 380-386
4 Yang, H. J., Liu, V. W., Wang, Y., Tsang, P. C. and Ngan, H. Y. (2006) Differential DNA methylation profiles in gynecological cancers and correlation with clinico-pathological data. BMC Cancer 6,212

5 Liedtke, C., Zschemisch, N. H., Cohrs, A., Roskams, T., Borlak, J., Manns, M. P. and Trautwein, C. (2005) Silencing of caspase-8 in murine hepatocellular carcinomas is mediated via methylation of an essential promoter element. Gastroenterology 129 , 1602-1615

6 Baylin, S. B. and Herman, J. G. (2000) DNA hypermethylation in tumorigenesis: epigenetics joins genetics. Trends Genet. 16, 168-174

7 Klose, R. J. and Bird, A. P. (2006) Genomic DNA methylation: the mark and its mediators. Trends Biochem. Sci. 31, 89-97

8 Sansom, O. J., Maddison, K. and Clarke, A. R. (2007) Mechanisms of disease: methyl-binding domain proteins as potential therapeutic targets in cancer. Nat. Clin. Pract. Oncol. 4, 305-315

9 Nan, X., Ng, H. H., Johnson, C. A., Laherty, C. D., Turner, B. M., Eisenman, R. N. and Bird, A. (1998) Transcriptional repression by the methyl-CpG-binding protein MeCP2 involves a histone deacetylase complex. Nature 393, 386-389

10 Koch, C. and Stratling, W. H. (2004) DNA binding of methyl-CpG-binding protein MeCP2 in human MCF7 cells. Biochemistry 43, 5011-5021

11 Klose, R. J., Sarraf, S. A., Schmiedeberg, L., McDermott, S. M., Stancheva, I. and Bird, A. P. (2005) DNA binding selectivity of $\mathrm{MeCP} 2$ due to a requirement for $A / T$ sequences adjacent to methyl-CpG. Mol. Cell 19, 667-678

12 Zhang, Y., Ng, H. H., Erdjument-Bromage, H., Tempst, P., Bird, A. and Reinberg, D. (1999) Analysis of the NuRD subunits reveals a histone deacetylase core complex and a connection with DNA methylation. Genes Dev. 13, 1924-1935

13 Kondo, E., Gu, Z., Horii, A. and Fukushige, S. (2005) The thymine DNA glycosylase MBD4 represses transcription and is associated with methylated p16(INK4a) and hMLH1 genes. Mol. Cell. Biol. 25, 4388-4396

14 Jorgensen, H. F., Ben-Porath, I. and Bird, A. P. (2004) Mbd1 is recruited to both methylated and nonmethylated CpGs via distinct DNA binding domains. Mol. Cell. Biol. 24, 3387-3395

15 Villa, R., Morey, L., Raker, V. A., Buschbeck, M., Gutierrez, A., De Santis, F., Corsaro, M., Varas, F., Bossi, D., Minucci, S. et al. (2006) The methyl-CpG binding protein MBD1 is required for PML-RAR $\alpha$ function. Proc. Natl. Acad. Sci. U.S.A. 103, 1400-1405

16 Sarraf, S. A. and Stancheva, I. (2004) Methyl-CpG binding protein MBD1 couples histone $\mathrm{H} 3$ methylation at lysine 9 by SETDB1 to DNA replication and chromatin assembly. Mol. Cell 15, 595-605

17 Arunkumar, A., Vijayababu, M. R., Kanagaraj, P. Balasubramanian, K., Aruldhas, M. M. and Arunakaran, J. (2005) Growth suppressing effect of garlic compound diallyl disulfide on prostate cancer cell line (PC-3) in vitro. Biol. Pharm. Bull. 28, 740-743

18 Albini, A., Benelli, R., Noonan, D. M. and Brigati, C. (2004) The "chemoinvasion assay": a tool to study tumor and endothelial cell invasion of basement membranes. Int. J. Dev. Biol. 48, 563-571

19 Bernard, D., Gil, J., Dumont, P., Rizzo, S., Monte, D., Quatannens, B., Hudson, D., Visakorpi, T., Fuks, F. and de Launoit, Y. (2006) The methyl-CpG-binding protein MECP2 is required for prostate cancer cell growth. Oncogene 25, 1358-1366

20 O'Hagan, R. C., Ohh, M., David, G., de Alboran, I. M., Alt, F. W., Kaelin, Jr, W. G. and DePinho, R. A. (2000) Myc-enhanced expression of Cul1 promotes ubiquitin-dependent proteolysis and cell cycle progression. Genes Dev. 14, 2185-2191 
21 Hermeking, H., Rago, C., Schuhmacher, M., Li, Q., Barrett, J. F., Obaya, A. J., O'Connell, B. C., Mateyak, M. K., Tam, W., Kohlhuber, F. et al. (2000) Identification of CDK4 as a target of c-MYC. Proc. Natl. Acad. Sci. U.S.A. 97, 2229-2234

22 Berns, K., Hijmans, E. M. and Bernards, R. (1997) Repression of c-Myc responsive genes in cycling cells causes G1 arrest through reduction of cyclin E/CDK2 kinase activity. Oncogene 15, 1347-1356

23 Wagner, A. J., Meyers, C., Laimins, L. A. and Hay, N. (1993) c-Myc induces the expression and activity of ornithine decarboxylase. Cell Growth Differ. 4, 879-883

24 Pfeifer, G. P. and Dammann, R. (2005) Methylation of the tumor suppressor gene RASSF1A in human tumors. Biochemistry (Moscow) 70, 576-583

25 Sears, R. C. (2004) The life cycle of c-myc: from synthesis to degradation. Cell Cycle 3, 1133-1137

26 Sears, R., Nuckolls, F., Haura, E., Taya, Y., Tamai, K. and Nevins, J. R. (2000) Multiple Ras-dependent phosphorylation pathways regulate Myc protein stability. Genes Dev. 14, 2501-2514
27 Dietze, E. C., Caldwell, L. E., Marcom, K., Collins, S. J., Yee, L., Swisshelm, K., Hobbs, K. B., Bean, G. R. and Seewaldt, V. L. (2002) Retinoids and retinoic acid receptors regulate growth arrest and apoptosis in human mammary epithelial cells and modulate expression of CBP/p300. Microsc. Res. Tech. 59, 23-40

28 Ballestar, E., Paz, M. F., Valle, L., Wei, S., Fraga, M. F., Espada, J., Cigudosa, J. C., Huang, T. H. and Esteller, M. (2003) Methyl-CpG binding proteins identify novel sites of epigenetic inactivation in human cancer. EMBO J. 22, 6335-6345

29 Fujita, N., Shimotake, N., Ohki, I., Chiba, T., Saya, H., Shirakawa, M. and Nakao, M. (2000) Mechanism of transcriptional regulation by methyl-CpG binding protein MBD1. Mol. Cell. Biol. 20, 5107-5118

30 Georgel, P. T., Horowitz-Scherer, R. A., Adkins, N., Woodcock, C. L., Wade, P. A. and Hansen, J. C. (2003) Chromatin compaction by human MeCP2. Assembly of novel secondary chromatin structures in the absence of DNA methylation. J. Biol. Chem. 278 32181-32188

Received 22 April 2008/23 June 2008; accepted 31 July 2008

Published as Immediate Publication 31 July 2008, doi 10.1042/BSR20080032 